\title{
Laparoscopic Versus Open Pyeloplasty for Management of Secondary Ureteropelvic Junction Obstruction
}

\author{
Hassaan A. Gad*1, M. Zaki Eldahshoury', Mohammed M. Hussein, Ahmed Hammady ${ }^{2}$ \\ ${ }^{1}$ Department of Urology, Faculty of Medicine, Aswan University, Aswan, Egypt \\ ${ }^{2}$ Department of Urology, Faculty of Medicine, Sohag University, Sohag, Egypt \\ *Corresponding author: Hassaan Ali Ahmed, Mobile: (+20) 01113730199, E-Mail: hassan.ali@aswu.edu.eg
}

\begin{abstract}
Background: Ureteropelvic junction obstruction (UPJO) causes hydronephrosis and progressive renal impairment may ensue if left uncorrected. Open pyeloplasty remains the standard against which new techniques must be compared.

Objective: To evaluate the laparoscopic management of secondary pelvi-ureteric junction obstruction regarding the operative time. Bleeding requiring blood transfusion intraoperative complication, hospital stays short- and longterm complication, and the rate of success in comparison to open repair in literature.

Patients and methods: This study was conducted at the Urology Department of Aswan and Sohag University Hospitals. In the period from April 2016 to April 2020, a total of forty-five patients with secondary PUJ obstruction fulfilling the inclusion criteria were admitted for undergoing laparoscopic pyeloplasty.

Results: The median follow-up period was 24 months (6-36 months). The mean of operative time (LPP) was $154.9 \pm$ 25.4 minutes, ranged from 80 to 185 minutes, and the mean of blood loss was $77.8 \pm 32.8 \mathrm{ml}$, ranged from 30 to 190

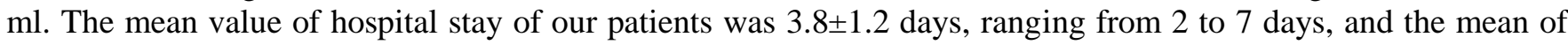
follow-up was $5.6 \pm 2.15$ months, ranged from 3 to 24 months. During the follow up there were three patients who experienced postoperative obstruction, our success rate was $93.3 \%$.

Conclusion: Laparoscopic pyeloplasty regarding cost-effectiveness, success rate, complications, and outcome the disadvantages of longer operative time of laparoscopi pyeloplasty, and the long learning curve, is more superior to open pyeloplasty in shorter hospital stay, early convalescence, and low postoperative analgesic requirements.
\end{abstract}

Keywords: Open pyeloplasty, Laparoscopic pyeloplasty, Redo pyeloplasty, UPJO

\section{INTRODUCTION}

Open pyeloplasty has been the gold standard for surgical treatment of ureteropelvic junction (UPJ) obstruction, enjoying a long-term success rate exceeding $90 \%{ }^{(\mathbf{1})}$.

Ureteropelvic junction obstruction. is the most common congenital abnormality of the upper urinary tract, open pyeloplasty has been the gold standard for UPJO repair Since the first successful reconstruction of an obstructed UPJO was accomplished in $1892^{(2)}$, and achieves success rates exceeding $90 \%{ }^{(3)}$.

Open pyeloplasty originally described by Andersen et al. ${ }^{(4)}$ remains the gold standard against which new techniques must be compared. The morbidity associated with flank incision, however, has led to the development of minimally invasive approaches to UPJ repair. Over the last two decades, the treatment approach to UPJ obstruction has evolved from open pyeloplasty to various minimally invasive procedures like endopyelotomy, acucise catheter incision, balloon dilatation, and laparoscopic pyeloplasty. These minimally invasive options are reported to have been less successful than open pyeloplasty ${ }^{(5)}$.

Laparoscopic dismembered pyeloplasty represents a minimally invasive alternative of gold standard open Anderson- Hynes technique that has a comparable successful outcome with open pyeloplasty while avoiding its comorbidity. It is also better than endopylotomy as it deals effectively with the crossing vessel $^{\left({ }^{(6)} \text {. }\right.}$

In cases of failed pyeloplasty open redo provides excellent results, with reported success rates of 77.8 $100 \%$ and have been suggested to be the first-choice method for repair ${ }^{(7)}$.

Laparoscopic pyeloplasty has recently been shown to have excellent success rates for persistent UPJO after a previously failed procedure ${ }^{(8)}$.

This work aims to evaluate the laparoscopic management of secondary pelviureteric junction obstruction regarding the operative time, bleeding requiring blood transfusion intraoperative complication, hospital stays short and long term complication and the rate of success.

\section{PATIENTS AND METHOD}

This study was conducted at the Urology Department of Aswan and Sohag University Hospitals. In the period from April 2016 to April 2020, a total of fortyfive patients with secondary PUJ obstruction fulfilling the inclusion criteria were admitted for undergoing laparoscopic pyeloplasty.

Inclusion criteria: All adult patients with PUJ obstruction after renal surgery (open, endoscopic, or laparoscopic previously repaired).

Exclusion criteria:

1. Patient having poor ipsilateral renal function $<15 \%$. 
2. Patients with UPJO require procedures other than pyeloplasty as

a. Obstruction of neoplastic nature.

b. Severe uncompensated cardiopulmonary disease.

c. Pediatric patient.

d. Pregnant women.

Ethical approval and written informed consent: Approval of the study was obtained from Aswan University academic and ethical committee. Every patient signed informed written consent for the acceptance of the operation.

\section{All Patients individuals were subjected to: \\ Preoperative evaluation:}

Detailed history.

Physical examination.

Routine laboratory work-up:

- Renal function evaluation.

- Bleeding and coagulation profile.

- Liver function evaluation.

- Blood sugar level.

- Urine analysis.

Medical fitness for surgical intervention.

Imaging studies:

- Renal US.

- Contrast study (IVU or CTU).

- Diuretic renogram.

- Retrograde pyelography when needed.

\section{Operative technique:}

Indications of pyeloplasty in our patients were persistent flank pain, recurrent febrile infection and infected hydronephrosis with subsequent percutaneous nephrostomy, in addition to radiological obstruction and persistence of symptoms after the initial repair, the obstructive pattern was individually confirmed by diuretic renal dynamic scan, using diethylene triamine penta acetic acid (DTPA) in all cases and further clarified anatomically by an intravenous urography (IVU) or contrast-enhanced CT. Preoperative preparations included mechanical bowel preparation on the night before the surgery and intravenous 3rd generation cephalosporin 2 hours before surgery.

Anesthesia: General anesthesia.

\section{Procedure:}

1- Anderson-Hynes dismembered pyeloplasty.

2- Double J stent for one month.

\section{Laparoscopic pyeloplasty:}

The patient was positioned in the modified flank position $\left(60^{\circ}\right)$. The back of the patient was supported by 2 gel-padded supports placed at the level of the upper back and the buttocks. The arms and the pressure areas were also padded by similar gel-padded supports. Then the patient was fixed to the table, disinfected, and draped. Pneumoperitoneum was created using a Veress needle inserted through a supraumbilical small stab incision and a low flow insufflation began. Then the pressure was raised until intraperitoneal pressure reached $14 \mathrm{mmHg}$. The first trocar $(10 \mathrm{~mm}$ camera trocar) was inserted under vision through the same supraumbilical incision. The intraperitoneal cavity was inspected by telescope for any inadvertent injury during trocar insertion. The second $5 \mathrm{~mm}$ trocar was placed in the midclavicular line 2 inches below the costal margin. The third $10 \mathrm{~mm}$ trocar was placed lateral to the rectus muscle at the level of the anterior superior iliac spine. In right-sided pyeloplasty, a fourth trocar was inserted below the xiphisternum for liver retraction. Incision of the line of Toldt and mobilization of the colon was the first step of the transperitoneal approach. To expose renal hilum in right-sided cases, the Kocher maneuver was used to mobilize the duodenum. Next, the ureter was identified and dissected cephalad tell UPJ.

If a crossing vessel is identified, the segment of the upper ureter beneath the crossing vessel should be freed completely from the vessel to enable ureter transposition. The renal pelvis was freed up as much as possible to enable tension-free anastomosis, A 4/0 polysorbe stay suture was taken in the lateral aspect of the ureter distal to UPJO to identify the correct orientation after dismembering the ureter. The diseased segment was excised; the ureter was spatulated laterally for $1.5 \mathrm{~cm}$. In the setting of a large or redundant renal pelvis, a renal pelvic reduction was done. A full-thickness anastomosis was started from the angle of V shape spatulation to the lower pole of the renal pelvis. Freehand intracorporeal interrupted or continuous $5 / 0$ polysorbe suture was used to complete the anastomosis. The renal pelvis was closed after ensuring that the DJ stent in its place.

Perinephric fat and Gerota's fascia were closed over the anastomosis after placing an $18 \mathrm{Ch}$ drain. The intra-peritoneal pressure was decreased to a level of 5 $\mathrm{mmHg}$ to ensure good hemostasis. Finally, the trocars were removed under vision, and the skin was closed by vicryl $2 / 0$ sutures. After recovery from anesthesia, the patient was transferred to his room. The patients were allowed to drink 6 hours after recovery from anesthesia.

Postoperative pain management by non-steroidal anti-inflammatory or opioids if needed. The patient was clinically monitoring for vital signs, pain score, bleeding, leakage, wound healing and symptoms was done all over the entire patient's hospital stay. The drain was removed when output was less than 100 cc/day, usually after 2 days of operation in most cases. The patient was discharged from the hospital after drain removal and maintaining a solid diet. Catheter removal mostly occurred on the third postoperative day. A detailed discharge sheet was given to the patient with full data. Then the patient was followed up regularly in the outpatient clinic, till the removal of 
skin suture usually by the $10^{\text {th }}$ postoperative. DJ stent was removed after 4 weeks. Abdominal ultrasonography was done after DJ removal by one day.

The follow-up protocol included ultrasonography, and IVU, and diuretic renography 1 month after removal of the double-J stent in the sign of PUJ, then ultrasonography every 3 months.

Success was defined as relief of symptoms in addition to improvements in the imaging results. Failure was defined as the persistence or recurrence of symptoms and/or obstructive drainage pattern on ultrasonography, IVU, or diuretic renography during the follow-up period.

\section{Statistical analysis}

Data were collected throughout history, basic clinical examination, laboratory investigations, and outcome measures coded, entered, and analyzed using Microsoft Excel software. Data were then imported into Statistical Package for the Social Sciences (SPSS version 20. 0) software for analysis. According to the type of data, the qualitative represented as number and percentage, and the quantitative group was represented by mean \pm SD. The following tests were used to test differences for significance; Difference and association of qualitative variable by Chi-square test $\left(\mathrm{X}^{2}\right)$, and differences between quantitative independent groups by Mann Whitney test. P-value was set at $<0$. 05 for significant results.

\section{RESULTS}

This study included 24 females and 21 males, with the mean age of $30.2 \pm 7.5$ years (range 21 to 45 years), failed previous repair on the left side was in 29 cases while it was in 16 cases on the right side, regarding BMI it was ranging from 21to 30 with mean of $24.9 \pm 3.1$.

The mean time after the failure of primary pyeloplasty in both genders was $21.3 \pm 8.2$ months with rang (10-38 months), the preoperative total renal function by DTPA was $80.7 \pm 26.5$.

Table (1): Baseline demographic data.

\begin{tabular}{|l|c|}
\hline Age & $0.2 \pm 7.5$ \\
\hline $\begin{array}{l}\text { Sex } \\
\text { Male/female }\end{array}$ & $21 / 24$ \\
\hline $\begin{array}{l}\text { Diseased side } \\
\text { Rt./Lt. }\end{array}$ & $16 / 29$ \\
\hline $\begin{array}{l}\text { Body mass index } \\
\text { (kg/m2) }\end{array}$ & $24.9 \pm 3.1$ \\
\hline $\begin{array}{l}\text { Meantime of } \\
\text { failure/months }\end{array}$ & $21.3 \pm 8.2$ \\
\hline $\begin{array}{l}\text { Renal } \\
\text { function/DTPA/ml }\end{array}$ & $80.7 \pm 26.5$ \\
\hline
\end{tabular}

After recovery from anesthesia, the patient was monitoring of the vital signs, bowel movements, pain management was done routinely for all cases by intravenous NSIDs analgesia or narcotic in some patients if needed.

In this study, the postoperative hospital stays ranged from 2 to 7 days with a mean of (3.8 \pm 1.2$)$ days.

The observed complications were in $6(13.3 \%)$ patients which recorded during that period of hospital stay and classified according to Clavien's system:

Cl. I: Any deviation from the normal postoperative course without the need for pharmacological treatment or surgical, endoscopic, and radiological interventions (Nausea, Vomiting, ilus).

Cl. II: Complications that require pharmacological treatment with drugs like (Fever and Wound infection).

Cl. III: Complications requiring surgical, endoscopic, or radiological intervention as (DJ obstruction and re-stenosis).

two of them presented by the prolonged anastomotic leak through the drain $500 \mathrm{cc} / 24$ for one week post-operative and managed by insertion of folly's catheter and the leakage was stopped in the two cases after 4 and 5 days respectively (Clavien grade I), two other patients had urinary tract infection (UTI) (Clavien grade II) complaining of post-operative fever in which resolved by medical treatment mainly antipyretic and. antibiotics with no further complication and free urine analysis, in one patient presented by severe hematuria, was encountered and it was resolved on medical treatment (Clavien grade II).

Last patient compliant of paralytic ileus (Clavien grade II). and it was resolved by intestinal prokinetic drugs, no need for blood transfusion postoperatively in all patients.

Table (2): Early postoperative follow-up.

\begin{tabular}{|l|c|}
\hline \multicolumn{1}{|c|}{ Variable } & Number \\
\hline $\begin{array}{l}\text { Postoperative analgesia } \\
\text { Narcotic / NSIDs }\end{array}$ & $12 / 33$ \\
\hline Postoperative fever & 4 \\
\hline Postoperative paralytic ileus & $13.9(12-36)$ \\
\hline $\begin{array}{l}\text { Postoperative } \\
\text { ambulation/hours }\end{array}$ & $7.7(6-24)$ \\
\hline $\begin{array}{l}\text { Postoperative starting oral } \\
\text { intake/hours site }\end{array}$ & 0 \\
\hline $\begin{array}{l}\text { Postoperative port } \\
\text { infection }\end{array}$ \\
\hline
\end{tabular}

\section{Late postoperative complications:}

After DJ removal renal obstruction was noticed in three patients, one of them required reinsertion of DJ stent for 1 month then it was removed follow up reveled no signs of obstruction, in the other two cases had high grad of obstruction, the renal scan was done revealing a poorly functioning kidney with a split function of $<10 \%$ one of whom was symptomatic 
(infected hydronephrosis) and underwent nephrostomy tube insertion followed by nephrectomy, while the other was lost during follow up.

During the postoperative follow-up, symptomatic and imaging improvements were documented for the successful cases; with no late failure and no need for further redo repairs.

Table (3): Postoperative complications according to Clavien-Dindo classification.

\begin{tabular}{|l|c|c|c|}
\hline $\begin{array}{l}\text { Clavien } \\
\text { Grade }\end{array}$ & Number & Complication & Management \\
\hline Cl./0 & 39 & No & No \\
\hline Cl./I & 2 & $\begin{array}{c}\text { Prolonged } \\
\text { anastomotic } \\
\text { leak }\end{array}$ & $\begin{array}{l}\text { Folly's } \\
\text { catheter }\end{array}$ \\
\hline Cl./II & 4 & $\begin{array}{c}\text { Hematuria } \\
\text { illus } \\
\text { UTI }\end{array}$ & $\begin{array}{c}\text { medical } \\
\text { treatment } \\
\text { intestinal } \\
\text { prokinetic } \\
\text { Antibiotic }\end{array}$ \\
\hline Total & 45 & & \\
\hline
\end{tabular}

Success rate: Secondary Laparoscopic pyeloplasty was successful in terms of symptom relief and radiological improvement in 42patients, achieving a success rate of $93.3 \%$.

\section{DISCUSSION}

Subsequent evolution in endoscopic physiology and application together with advances in endoscopic technology fostered advances in the field. Current approaches include antegrade percutaneous, retrograde ureteroscopic guided laser, and retrograde acusize $₫$ balloon dilatation. The success rate of these minimally invasive options has consistently been less than with open pyeloplasty by $10-30 \%{ }^{(9)}$. The varied surgical anatomy of PUJ (huge dilatation, crossing vessels, high insertion of the ureter) compromises all of these endourological procedures. These procedures are also associated with a risk of perioperative hemorrhage and $3-11 \%$ of patients required blood transfusion ${ }^{(\mathbf{1 0})}$.

Postoperative hospital stay in Nishi et al. (11) study was 6.1 days (range 3-13) which is more than our postoperative hospital stay which is $3.8 \pm 1.2$ days and this may be due to the more postoperative complications in his study as paralytic ileus and hematuria. Bansal et al. ${ }^{(6)}$ a hospital stay $8.29 \pm 1.35$ days in his study of 34 patients in his study.

Also, Francesco et al. ${ }^{(12)}$ reported the mean postoperative hospital stay was $4.47 \pm 0.86$ days there is a significant difference regarding our study.

Postoperative complications in our study were $13.3 \%$ which is better than many works of literature, $17.5 \%$ complications were reported in the study of
Klinger et al. ${ }^{(13)}$ in the laparoscopic pyeloplasty group of in his comparative study which contain 55 patients.

Another study of Rassweiler et al. ${ }^{(14)}$ in his study of LP in 143 patients show 8 patients (5.5\%) need retreatment in the form of 4 patients need laser endopyelotomy, 3 patients need open pyeloplasty and one patient need open nephrectomy. Schuster et al. ${ }^{(15)}$ treated 44 patients by LP in which 2 patients need retreatment after the failed procedure, one patient needs open pyeloplasty, and the other patient underwent robot-assisted laparoscopic dismembered pyeloplasty, in our present study only 3 cases underwent retreatment of overall 45 patients. Also, Matin et al. (16) show in their study about laser endopyelotomy for treatment of PUJO in 45 patients a postoperative complication was $11.1 \%$ but with only success rate $65.4 \%$ of his patients.

With the advanced uses of Robotic in surgery in the last two decades. Many urologists use the technique of robotic-assisted urologic laparoscopy in the management of PUJO Niver et al. ${ }^{(\mathbf{1 7})}$ published the largest series of redo robotic-assisted pyeloplasty in adults with encouraging mid-term results which were $94.1 \%$.

Atug et al. ${ }^{(18)}$ reported 7 adult patients who had robotic-assisted dismembered LP and they compared their results with 37 patients of primary PUJO. Like with LP, their mean operative time was 60 min longer in their pyeloplasty group, but the hospital stay, blood loss, and success rates were similar between the two groups. Hemal et al. ${ }^{(19)}$ included 9 patients with secondary PUJO after failed open pyeloplasty, all of them showed both clinical and radiological improvement by $100 \%$.

Despite these overall excellent results of redo robotic-assisted LP both in adults and children, none of the previously mentioned reports compared the cost of robotic-assisted and conventional redo LP.

Many studies in the literature have reported the feasibility and high success rate of secondary LP after recurrent PUJO, Sundaram et al. ${ }^{(20)}$, reported an $83 \%$ success rate with laparoscopic pyeloplasty in 36 adult patients but with longer operative time. Similarly, Basiri et al. ${ }^{(21)}$, had reported a success rate of $77.8 \%$ but using different techniques during laparoscopic pyeloplasty in 18 patients. Likewise, Francesco et al. (12) reported their experience with mid-term follow-up for redo pyeloplasty after failed open repair in 38 patients, and their $92.1 \%$ success rate demonstrated the excellence of laparoscopic repair for these cases. The redo LPs in the present study thus have a high success rate $(90.6 \%)$ in the context of the previously reported series.

Percutaneous endopyelotomy has been indicated to be the first choice to treat PUJ obstruction after failed open pyeloplasty Basiri $\boldsymbol{e t}$ al. ${ }^{(21)}$ several options are used for managing the failed pyeloplasty: 
antegrade or retrograde laser endopyelotomy, balloon dilation, and open redo pyeloplasty ${ }^{(7)}$.

Di Grazia and Nicolosi ${ }^{(22)}$ reported success rates of only $66.6 \%$ for six patients treated with laser endopyelotomy and performed after failed pyeloplasty, which shows a low success rate with early recurrence.

Thomas et al. ${ }^{(7)}$ reported seven patients with failed pyeloplasty. Patients underwent initial balloon dilation, of which one was successful, and subsequently, six patients (86\%) underwent open surgery. In their series, failed pyeloplasties did not respond well to balloon dilation, probably because of scar formation with a mean success rate of only $(14 \%)$.

Due to low success rate and inconsistent long term results of minimally invasive procedures such as balloon dilation and endopyelotomy and their role in selected cases Using inclusion criteria of stricture $<2$ $\mathrm{cm}$, renal function $>25 \%$, and the absence of severe hydronephrosis So it can't be considered an ideal option in secondary PUJO management.in this study of 45patients achieving a success rate of $93.3 \%$ by symptom relief and radiological improvement ${ }^{(23)}$.

\section{CONCLUSION}

Laparoscopic pyeloplasty regarding costeffectiveness, success rate, complications and outcome the disadvantages of longer operative time of laparoscopi pyeloplasty, and long learning curve, is more superior to open pyeloplasty in shorter hospital stay, early convalescence, and low postoperative analgesic requirements. So, it can be considered as a gold standard in the treatment of secondary PUJO.

Conflict of interest: The authors declare no conflict of interest.

Funding sources: The authors have no funding to report.

\section{REFERENCES}

1. Troxel S, Das S, Helfer $\mathrm{E}$ et al. (2006): Laparoscopy versus dorsal lumpectomy for ureteropelvic junction obstruction repair. J Urol., 176:1073-6.

2. Kletscher B, Segura J, Le Roy A et al. (1995): Percutaneous antegrade endopyelotomy: a review of 50 consecutive 50 cases. Journal of Urology, 153:701-703.

3. Psooy K, Pike J, Leonard M (2003): Long-term followup of pediatric dismembered pyeloplasty: how long is long enough. Journal of Urology, 169(5):1809-1812.

4. Anderson J, Hynes W (1949): Retro-caval ureter: A case diagnosed preoperatively and treated successfully by a plastic operation. Br J Urol., 21:209-14.

5. Schuessler W, Grune M, Tecuanhuey $L$ et al. (1993): Laparoscopic dismembered pyeloplasty. J Urol., 150:1795-9.

6. Bansal P, Gupta A, Mongha $R$ et al. (2008): Laparoscopic versus open pyeloplasty: comparison of two surgical approaches - a single-center experience of three years. J Minim Access Surg., 4: 76-9.
7. Thomas J, DeMarco R, Donohoe J et al. (2005): Management of the failed pyeloplasty: a contemporary review. J Urol., 174: 2363-2366.

8. Zhang X, Li H, Ma X et al. (2006): Retrospective comparison of retroperitoneal laparoscopic versus open dismembered pyeloplasty for ureteropelvic junction obstruction. J Urol., 176:1077-80.

9. Baldwin D, Dunbar J, Wells N et al. (2003): Singlecenter comparison of laparoscopic pyeloplasty, Acusize endopyelotomy, and open pyeloplasty. J Endourol., 17:155-7.

10. Brooks J, Kavoussi L, Preminger G et al. (1995): Comparison of open and endourological approaches to the obstructed ureteropelvic junction. Urology, 46:791-5.

11. Nishi M, Tsuchida M, Ikeda $M$ et al. (2015): Laparoscopic pyeloplasty for secondary ureteropelvic junction obstruction: Long-term results. International Journal of Urology, 22: 368-371.

12. Francesco C, Maurizio F, Luigi $P$ et al. (2017): Laparoscopic management of recurrent ureteropelvic junction obstruction following pyeloplasty: a single surgical team experience. Int Braz J Urol., 43(3): 512-517.

13. Klinger $H$, Remzi $M$, Janetschek $G$ et al. (2003): Comparison of open versus laparoscopic pyeloplasty techniques in the treatment of ureteropelvic junction obstruction. Eur Urol., 44:340-46.

14. Rassweiler J, Subotic S, Feist-Schwenk M et al. (2007): Minimally invasive treatment of ureteropelvic junction obstruction: Long-term experience with an algorithm for laser endopyelotomy and laparoscopic retroperitoneal pyeloplasty. J Urol., 177:1000-5.

15. Schuster T, Jacobs B, Gayed B et al. (2010): Preliminary experience with laparoscopic ureteropelvic junction release in the treatment of ureteropelvic junction obstruction. J Endourol., 24:393-396.

16. Matin S, Yost A, Streem S (2003): Ureteroscopic laser endopyelotomy: a single-center experience. J Endourol., 17: 401-406.

17. Niver B, Agalliu L, Bareket R et al. (2012): Analysis of robotic-assisted laparoscopic pyeloplasty for primary versus secondary repair in 119 consecutive cases. Urology, 79: 689-94.

18. Atug F, Burgess S, Castle E et al. (2006): Role of robotics in the management of secondary ureteropelvic junction obstruction. Int J Clin Pract., 60: 9-11.

19. Hemal A, Mishra S, Mukharjee S et al. (2008): Robotassisted laparoscopic pyeloplasty in patients of ureteropelvic junction obstruction with previously failed open surgical repair. Int J Urol., 15: 744-6

20. Sundaram C, Grubb R, Rehman J et al. (2003): Laparoscopic pyeloplasty for secondary ureteropelvic junction obstruction. J Urol., 169:2037-4.

21. Basiri A, Behiati S, Zand S et al. (2007): Laparoscopic pyeloplasty in secondary ureteropelvic junction obstruction after failed open surgery. J Endourol., 21:1045-1051.

22. Di Grazia E, Nicolosi D (2005): Ureteroscopic laser endopyelotomy in secondary UPJ obstruction after pyeloplasty failure. Urol Int., 75: 333-6.

23. Butani R, Eshghi M (2008): Cold-knife retrograde endopyelotomy: a long-term follow-up. J. Endourol., 22, $657-660$. 